\title{
Experimental Assessment on the Flexural Bonding Performance of Concrete Beam with GFRP Reinforcing Bar under Repeated Loading
}

\author{
Minkwan $\mathrm{Ju}^{1}$ and Hongseob $\mathrm{Oh}^{2}$ \\ ${ }^{1}$ Department of Civil Engineering, Kangwon National University, 1 Joongang-ro, Samcheok-si, Gangwon 245-711, Republic of Korea \\ ${ }^{2}$ Department of Civil Engineering, Gyeongnam National University of Science and Technology, 150 Chilam-dong, Jinju, \\ Gyeongnam 660-758, Republic of Korea
}

Correspondence should be addressed to Hongseob Oh; opera69@chol.com

Received 14 April 2015; Accepted 7 June 2015

Academic Editor: Joao M. L. Reis

Copyright (C) $2015 \mathrm{M}$. Ju and H. Oh. This is an open access article distributed under the Creative Commons Attribution License, which permits unrestricted use, distribution, and reproduction in any medium, provided the original work is properly cited.

\begin{abstract}
This study intends to investigate the flexural bond performance of glass fiber-reinforced polymer (GFRP) reinforcing bar under repeated loading. The flexural bond tests reinforced with GFRP reinforcing bars were carried out according to the BS EN 12269 1 (2000) specification. The bond test consisted of three loading schemes: static, monotonic, and variable-amplitude loading to simulate ambient loading conditions. The empirical bond length based on the static test was $225 \mathrm{~mm}$, whereas it was $317 \mathrm{~mm}$ according to ACI 440 1R-03. Each bond stress on the rib is released and bonding force is enhanced as the bond length is increased. Appropriate level of bond length may be recommended with this energy-based analysis. For the monotonic loading test, the bond strengths at pullout failure after 2,000,000 cycles were $10.4 \mathrm{MPa}$ and $6.5 \mathrm{MPa}$, respectively: $63-70 \%$ of the values from the static loading test. The variable loading test indicated that the linear cumulative damage theory on GFRP bonding may not be appropriate for estimating the fatigue limit when subjected to variable-amplitude loading.
\end{abstract}

\section{Introduction}

Fiber-reinforced polymer (FRP) bars have been used widely in reinforced concrete structures due to their many advantages; FRP bars have superior material properties, such as a high tensile strength and corrosion resistance. From a maintenance point of view, using FRP bars inside concrete structures is clearly cost-effective with respect to life cycle costs. Although the bond performance of FRP bars is weaker than that of steel bars, FRP bars have generated interest as an advanced substitute material for reinforced concrete structures.

The bond in reinforced concrete is important in transferring stress from the reinforcing bar to the concrete. To have a composite action in reinforced concrete, perfect bond capacity is required, and conventional steel bars are usually considered to satisfy this bond performance. Unlike conventional steel reinforcing bars, however, determining the performance bond capacity of FRP reinforcing bars is difficult. The bond between concrete and FRP reinforcing bars is complex and several factors influence the bond characteristics. According to previous research, the key factors are the concrete compressive strength, bar diameter, embedment length, geometry and surface treatment scheme of the FRP reinforcing bar, temperature changes, and environmental conditions [1].

Many experimental studies have been conducted to investigate the bond performance of FRP reinforcing bars using pullout tests [2-7]. Most of these have been monotonic and uniaxial tests based on the ASTM standard. Beam tests are believed to more realistically simulate the stress transfer of reinforced concrete subjected to flexural bending, but few studies have been reported determining the fatigue bond characteristics of FRP reinforcing bars, which is essential to understand reinforced concrete structures in a service state under repeated monotonic and amplitude loading. Investigating bond characteristics of the bond surface is important, wherein longitudinal friction of the FRP reinforcing bar is 


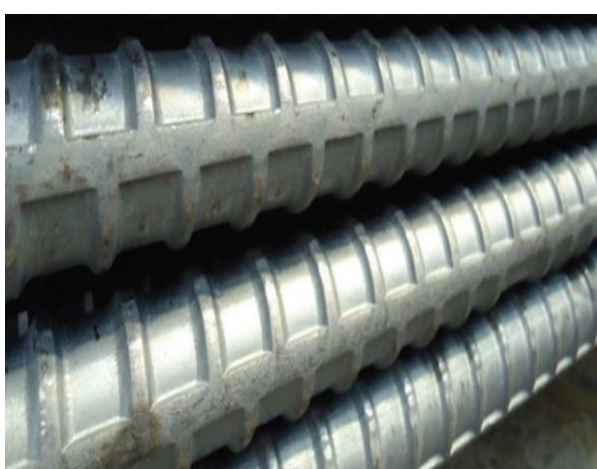

(a) Conventional steel reinforcing bar

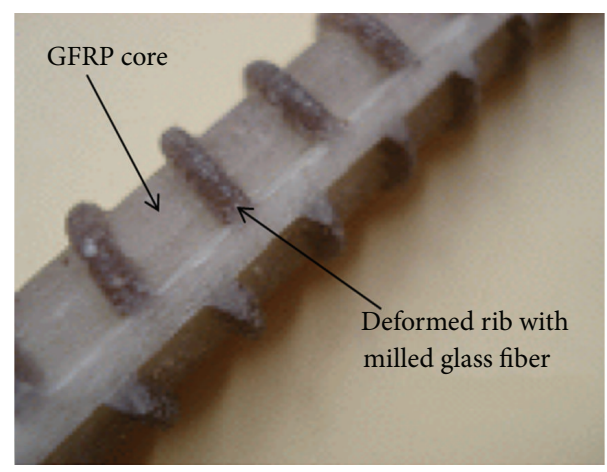

(b) Newly developed GFRP reinforcing bar

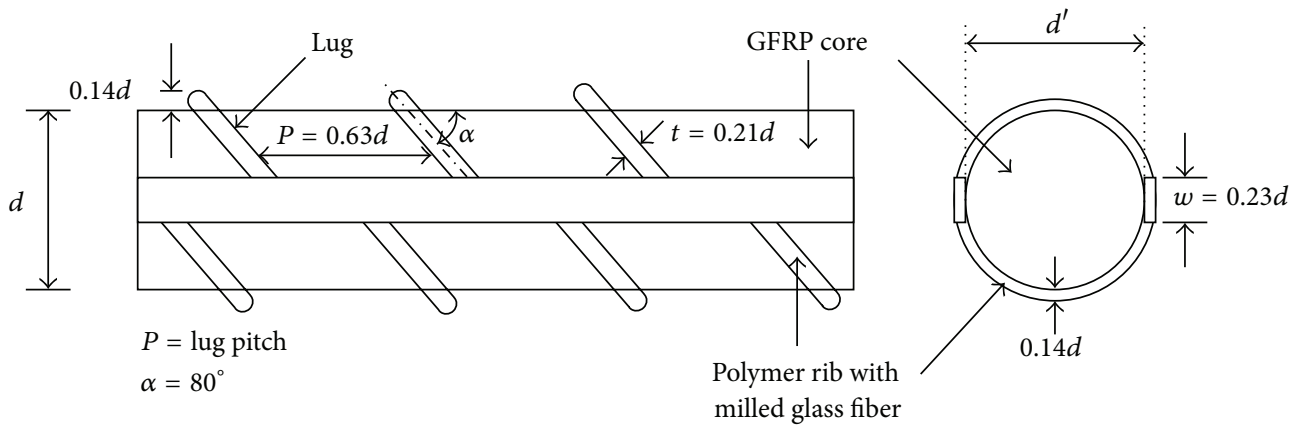

(c) Design detail of GFRP reinforcing bar

FIGURE 1: GFRP reinforcing bar used in this study.

usually concentrated when subjected to repeated external loading of the reinforced concrete beam.

This study investigated the bond performance of GFRP reinforcing bars subjected to fatigue loading. The beam tests for bonding were carried out according to the BS EN 122691 [8] specification. The test variables were the three types of bond length. For static and monotonic loading tests, maximum bond strength and slip were analyzed, and a reduction factor in bond strength was suggested experimentally to evaluate safety in bond design subjected to fatigue loading. For variable-amplitude loading tests, the fatigue limit was evaluated with an S-N curve based on Miner's theory, and its application to the nonlinear cumulative damage for the bonding behavior of glass fiber-reinforced polymer (GFRP) reinforcing bars subjected to variable-amplitude loading is discussed.

\section{Experimental Program}

2.1. Description of Properties of GFRP Reinforcing Bars, Steel Reinforcing Bars, and Concrete. The GFRP reinforcing bar, as depicted in Figure 1, used consisted of continuous longitudinal glass fibers of $67 \%$ volume fraction in a thermosetting epoxy [9]. To mold the surface pattern and to enhance the bond performance of the GFRP reinforcing bar, its external layer was manufactured by mixing milled glass fiber and epoxy at a ratio of $1: 1$, and it was cured for $15 \mathrm{~min}$ at a temperature above $160^{\circ} \mathrm{C}$. To enhance bond performance, the surface pattern of the developed GFRP reinforcing bar was treated to have ribs similar to those of a steel reinforcing bar using epoxy resin containing milled glass fiber by mechanical pressing after pultrusion of the FRP core section. The rib section was a mixture of epoxy resin and milled glass fibers. The external deformed-rib arrangement angle was set at $80^{\circ}$. The rib height and spacing were chosen based on a literature review to obtain optimal mechanical performance in terms of bond and tension characteristics [10]. The GFRP reinforcing bar used for the tensile area had a nominal diameter of $9.53 \mathrm{~mm}$ and a design tensile strength which is a guaranteed tensile strength multiplied by the environmental reduction factor in compliance with ACI 440 1R-06 of fu (GFRP) = $616 \mathrm{MPa}$; its modulus of elasticity was $42.9 \mathrm{GPa}$ [11].

2.2. Flexural Bond Strength from the Beam Test. The test method and details for evaluating the flexural bond strength of the GFRP reinforcing bar adopted the scheme of the British Standard [8]. The beam test in bonding is considered to more realistically mimic the stress conditions of the reinforced concrete (RC) structure subjected to bending. Tighiouart et al. [12] conducted beam tests in bonding according to the RILEM specification. The specimen consisted of two rectangular blocks joined at the top by a steel ball joint. The design concrete compressive strength is $27 \mathrm{MPa}$. This specimen detail may not be appropriate for fatigue but for a monotonic loading test due to the possibility of the stress concentration in the concrete at the ball joint. Thus, for the fatigue bond test in this study, the test scheme of BS EN 122691 [8] was adopted, whereby a concrete compressive block was used to create the stress distribution in the fatigue test. 


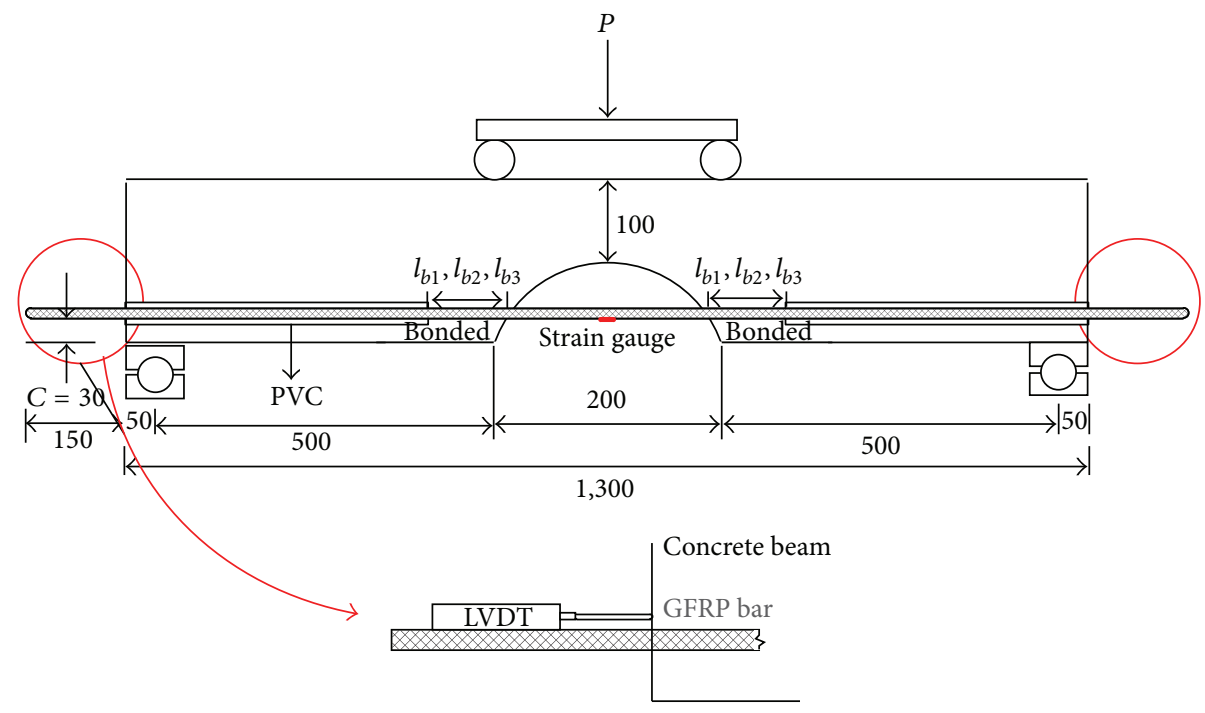

FIGURE 2: Specimen geometry of the BS beam test.
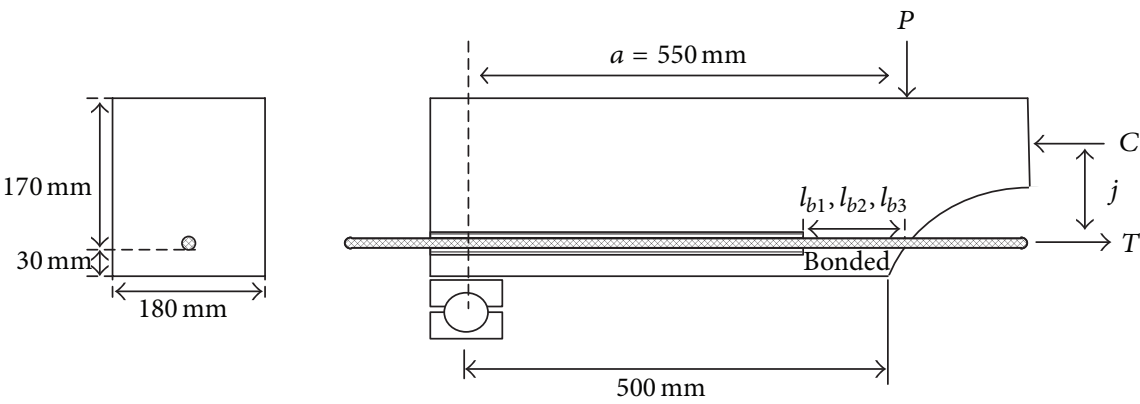

FIGURE 3: Force equilibrium of cross section at the mid-span.

The size of the test specimens was $180 \times 200 \times 1300 \mathrm{~mm}$, and the major variables according to bond length $\left(l_{b}\right)$ are shown in Figure 2. The lower section of the mid-span in the beam was formed as a semicircular type to prevent stress concentration caused by flexural cracks tips. Bond lengths were set at $l_{b 1}=5 d_{b}(45 \mathrm{~mm}), l_{b 2}=10 d_{b}(90 \mathrm{~mm})$, and $l_{b 3}=15 d_{b}(135 \mathrm{~mm})$, where $d_{b}$ is the diameter of the FRP reinforcing bar, for simulating pullout failure of the GFRP reinforcing bar. As shown in Figure 2, the unbounded region of the FRP reinforcing bar in the concrete beam was secured by PVC pipes that had a slightly larger inner diameter than the diameter of the GFRP reinforcing bar. The test beam was loaded using a $250 \mathrm{kN}$ hydraulic actuator (MTS) and was executed with a four-point loading method. The unloaded slip was measured at both ends of the specimens (Figure 2).

Figure 3 illustrates the force equilibrium condition, and its relationship is shown in (1). Once the tensile load $(T)$ is applied, the tensile stress $(\tau)$ at the load level is calculated by dividing by the bond surface area according to BS EN 12269-1 [8]. The optimal bond length is defined as the minimum length to transfer the ultimate load from the GFRP reinforcing bar to the concrete through the bond surface. Consider

$$
M=P \cdot a=C \cdot j=T \cdot j=E_{\mathrm{frp}} \cdot \varepsilon_{\mathrm{frp}} \cdot j,
$$

where $T=$ tensile load of the GFRP reinforcing bar $(\mathrm{kN}), P$ $=$ ultimate applied load $(\mathrm{kN}), \varepsilon_{\mathrm{frp}}=$ measured strain of the steel or GFRP reinforcing bar, $E_{\text {frp }}=$ modulus of elasticity of the steel or GFRP reinforcing bar (MPa), $a=$ shear span $(\mathrm{mm})$, and $j=$ distance between the resulting tensile and compressive loads ( $\mathrm{mm}$ ).

As mentioned above, the fatigue loading applied maximum stress level with the ratio to the static test results as follows: $60 \%, 70 \%, 75 \%, 80 \%, 85 \%$, and $90 \%$ of the peak load of each variable. The minimum stress level was considered to be $10 \%$ of the applied maximum load. All specimens were tested at $3 \mathrm{~Hz}$, and sinusoidal loading was controlled up to fatigue failure or 2,000,000 loading cycles. Data acquisition for calculating bond stress was performed after finishing the cycle controls. 
TABLE 1: Experimental bond strength and slip at peak stress.

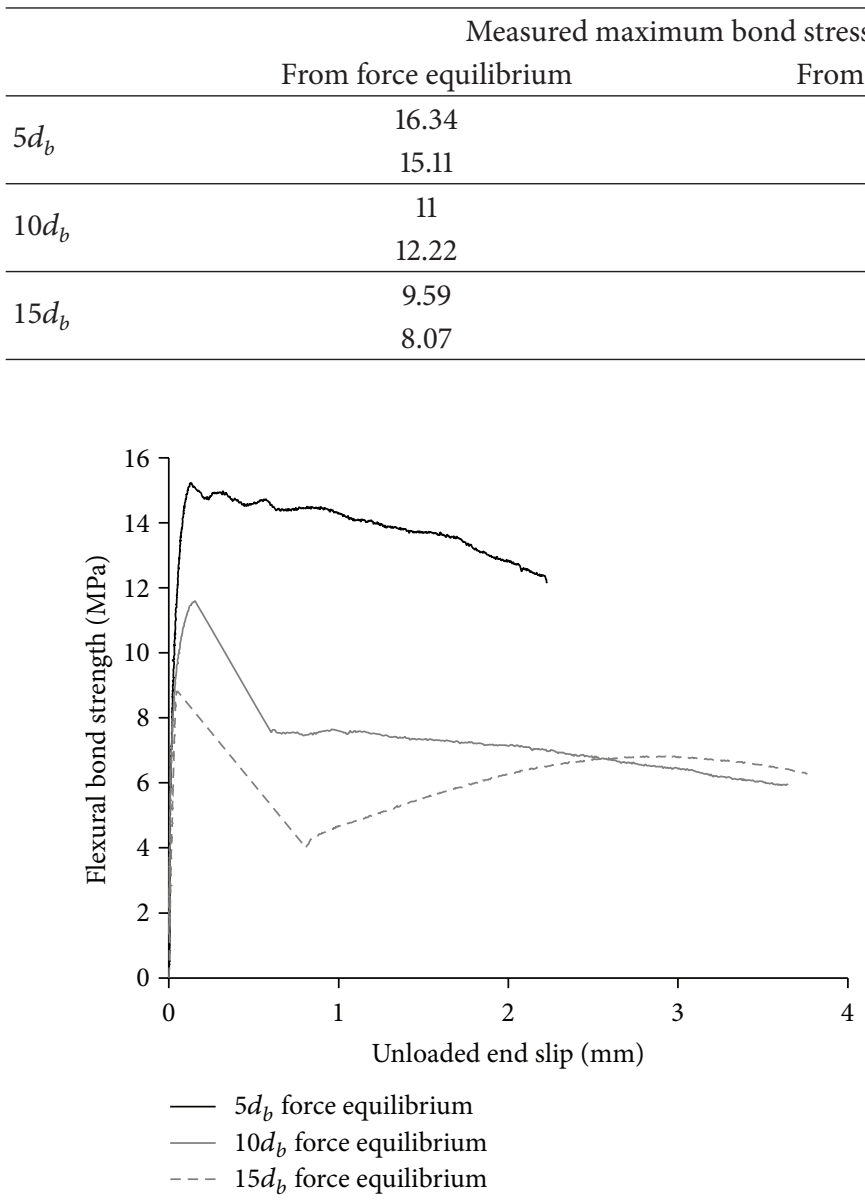

(a)

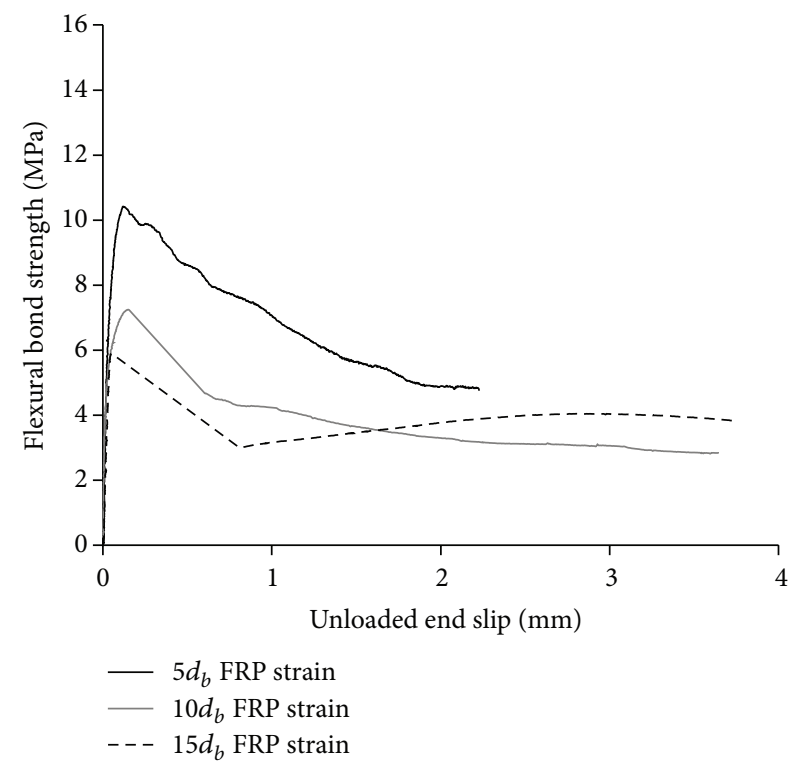

(b)

FIGURE 4: Relationship between flexural bond stress and slip under static loading conditions.

\section{Test Results of the Static Loading Test}

The relationship between flexural bond stress and slip from the static test, performed according to Oh et al. [11], is summarized in Figure 4 and Table 1. The bond stress of each specimen was expressed under force equilibrium conditions and reinforcing bar strain. According to the static loading test, the bond strength determined using the measured strain of the GFRP reinforcing bar was found experimentally to be lower than that using equilibrium theory. This difference might have been caused by incomplete bond stress transfer to the concrete. The reason was analyzed in terms of the bond behavior of the GFRP reinforcing bar and the change in the neutral axis of the beam section during loading.

As reported by other researchers, the bond strength calculated from force equilibrium at the beam section of the mid-span of the specimen is slightly higher than the strength calculated from FRP strain. The work energy of the pullout action of FRP reinforcing bar indicates the capacity for energy dissipation at the interface between concrete and the surface of reinforcing bar. While the bond strength decreases, according to the increase in bond length, total work energy, defined by the area of loads and slip curves of the specimen, increases (Figure 5).

The required development length to ensure reinforcing bar strength should be calculated under force equilibrium conditions for the beam specimen and also demonstrated by the equation $l_{b}=d_{b} f_{\text {fu }} / 18.5$, as reported in ACI $4401 \mathrm{R}$ 03 , where $l_{b}$ is the bond length, $d_{b}$ is the nominal diameter of the GFRP reinforcing bar, and $f_{\mathrm{fu}}$ is the designed tensile strength of the GFRP reinforcing bar. The experimental length obtained from the regression data based on the test results and development length according to ACI 440 is shown in Figure 6. Both the regression curve from test results and the analytical bond length from (1) curve tended to decrease the bond strength as the bond length increased. The large discrepancy at $50 \mathrm{~mm}$ bond length was due to the short bond length and bond perimeter, which could be conservative as the bond length is increased further. The minimum bond length that the GFRP reinforcing bar can afford to contribute to the tensile strength of the concrete was $225 \mathrm{~mm}$ from the crossing point between the two curves by regression and (1). The bond length, however, was calculated as $317 \mathrm{~mm}$ according to ACI $4401 \mathrm{R}-03$. 
TABLE 2: Stress levels in the fatigue bond test.

\begin{tabular}{|c|c|c|c|c|c|c|c|}
\hline Specimens & $\begin{array}{l}\text { Bond strength at } \\
\text { static test }(\mathrm{MPa})\end{array}$ & $\begin{array}{l}\text { Applied stress } \\
\text { level (\%) }\end{array}$ & $\begin{array}{l}\text { Applied bond } \\
\text { stress (MPa) }\end{array}$ & $\begin{array}{l}\text { Slip at ultimate } \\
\text { load }(\mathrm{mm})\end{array}$ & $\begin{array}{l}\text { Number of } \\
\text { cycles }\end{array}$ & $\begin{array}{c}\text { Residual bond } \\
\text { strength after } 2 \\
\text { million loadings } \\
(\mathrm{MPa})\end{array}$ & Failure mode \\
\hline \multirow{4}{*}{$5 d_{b}(45 \mathrm{~mm})$} & \multirow{4}{*}{15.1} & 70 & 11.4 & 0.175 & $2,000,000$ & 10.5 & \multirow{4}{*}{$\mathrm{P}^{*}$} \\
\hline & & 75 & 12.2 & - & $1,516,231$ & - & \\
\hline & & 80 & 13.0 & - & 29,268 & - & \\
\hline & & 90 & 14.7 & - & 3,804 & - & \\
\hline \multirow{2}{*}{$10 d_{b}(90 \mathrm{~mm})$} & \multirow{2}{*}{10.2} & 70 & 7.7 & 0.083 & $2,000,000$ & 6.4 & \multirow{2}{*}{$\mathrm{P}^{*}$} \\
\hline & & 80 & 8.8 & - & 81,063 & - & \\
\hline \multirow{4}{*}{$15 d_{b}(135 \mathrm{~mm})$} & \multirow{4}{*}{7.5} & 60 & 4.8 & - & $2,000,000$ & 3.9 & \multirow{4}{*}{$\mathrm{CS}^{* *}$} \\
\hline & & 75 & 6.0 & - & $1,981,582$ & - & \\
\hline & & 80 & 7.2 & - & 193,972 & - & \\
\hline & & 85 & 7.7 & - & 114,413 & - & \\
\hline
\end{tabular}

${ }^{*}$ Pullout failure and ${ }^{* *}$ concrete splitting failure.

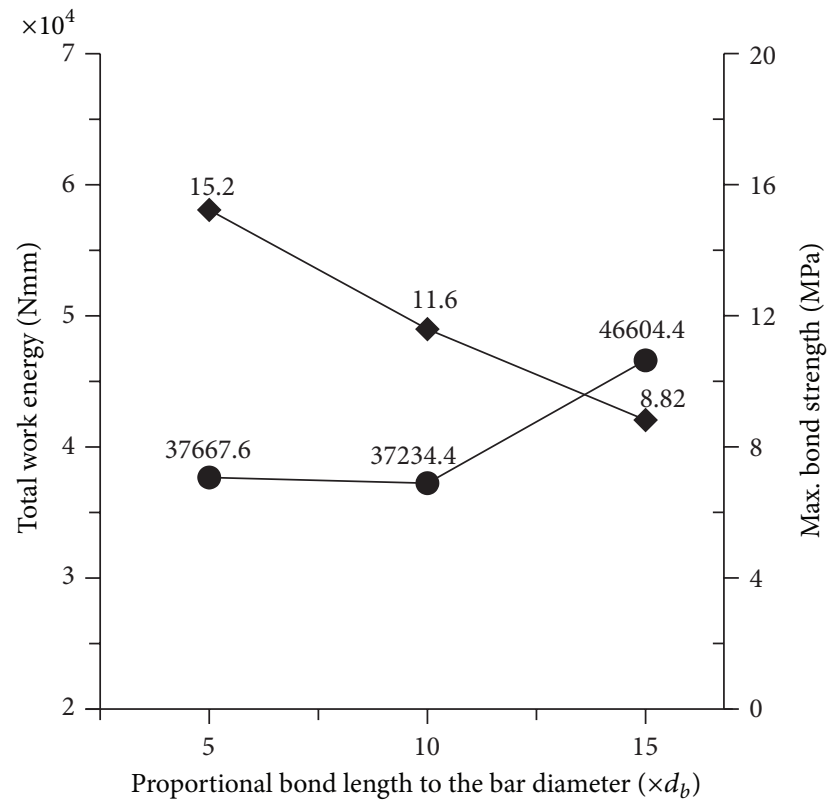

FIGURE 5: Total work energy and maximum bond strength according to the embedded bond length.

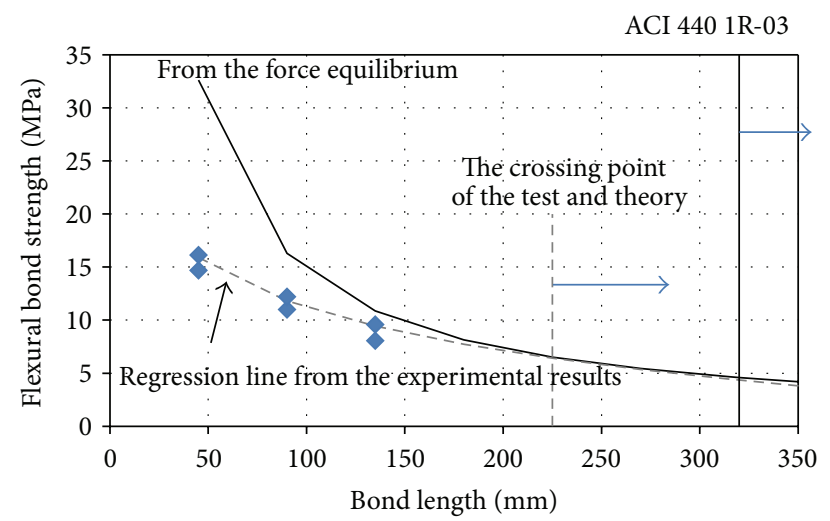

FIGURE 6: Bond strength and bond length relationship by calculation and test results.

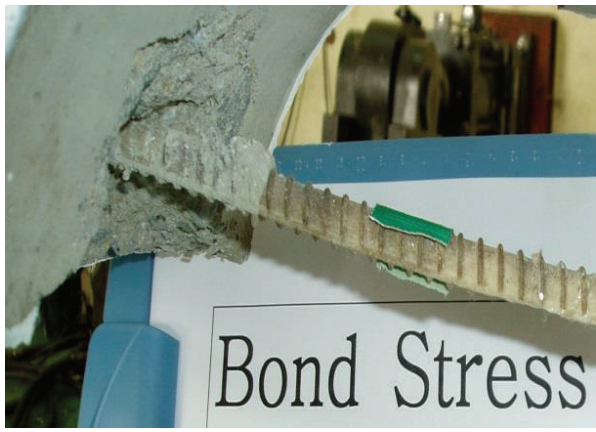

Figure 7: Pullout failure.

\section{Test Results of the Monotonic Fatigue Loading Test}

4.1. Bond Strength When Subjected to Fatigue Loading. Each specimen was tested for the designated level of stress as summarized in Table 2, and 10 specimens in total were tested. Two types of failure pattern were investigated: typical pullout failure $\left(5 d_{b}, 10 d_{b}\right)$ and concrete splitting failure at the end of bonded region of the reinforcing bar $\left(15 d_{b}\right)$ (Figures 7 and 8). Pullout failure occurs when the bond stress between the concrete and GFRP reinforcing bar exceeds the stress resulting from the tensile load on the bar. Concrete splitting failure must be caused by insufficient concrete strength, even though the embedded length of the reinforcing bar is sufficient to perform the composite action. As shown in Figure 6, no shear-off of the ribs on the GFRP reinforcing bar occurred with the pullout failure, indicating that the interlocking mechanism with the concrete is valid.

The bond strength was determined at the fatigue limit of 2,000,000 cycles, at which point a failure test was finally applied. The $5 d_{b}$ and $10 d_{b}$ specimens showed the fatigue limit at a stress level of $70 \%$. The number of cycles increased as the development length was longer. For the pullout failure specimens of $5 d_{b}$ and $10 d_{b}$, the bond strengths at failure testing after 2,000,000 cycles were $10.5 \mathrm{MPa}$ and $6.4 \mathrm{MPa}$, 


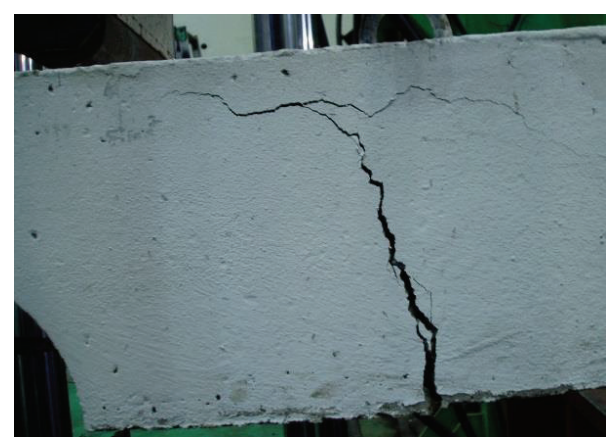

FIGURE 8: Concrete splitting failure.

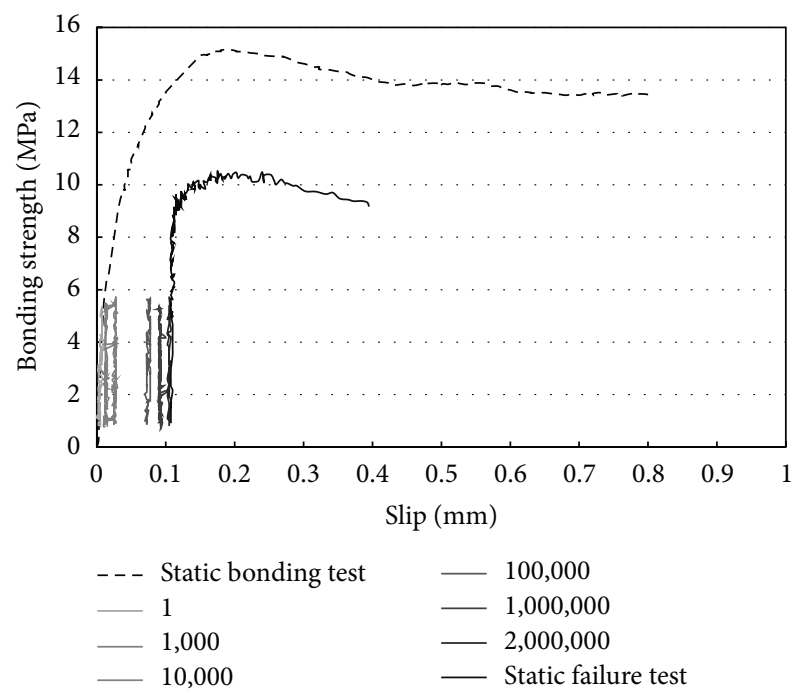

FIGURE 9: Bond stress-slip relationship of the $5 d_{b}$ specimen under $70 \%$ stress level of the ultimate strength.

respectively, which is $63-70 \%$ of those from the static bond test. This difference was caused by repeated stress on the bond surface so that fatigue stress weakened the adhesive capacity between the concrete and surface of the GFRP bar, including ribs, so that it degraded the bonding performance. For the $15 d_{b}$ specimen, the mode of failure was concrete splitting. The bond length over $15 d_{b}$ can be concluded to be close to having sufficient bonding performance for the GFRP reinforcing bar. This is consistent with the results of the static loading test, whereby the bond strength difference between the calculated and measured strain on the GFRP reinforcing bar and that using equilibrium theory keeps decreasing as the bond length increases.

4.2. Fatigue Bond Strength and Slip Relationship. Bond stress and slip relationships under fatigue loading are shown in Figures 9 and 10, including the results of the static bond tests. The $15 d_{b}$ specimen was not included for slip behavior after 2,000,000 cycles due to the concrete splitting mode of failure. The slip amount at 2,000,000 cycles for the $10 d_{b}$ specimen was not measured due to a data recording error. According to Oh et al. [11], the bond performance of the steel

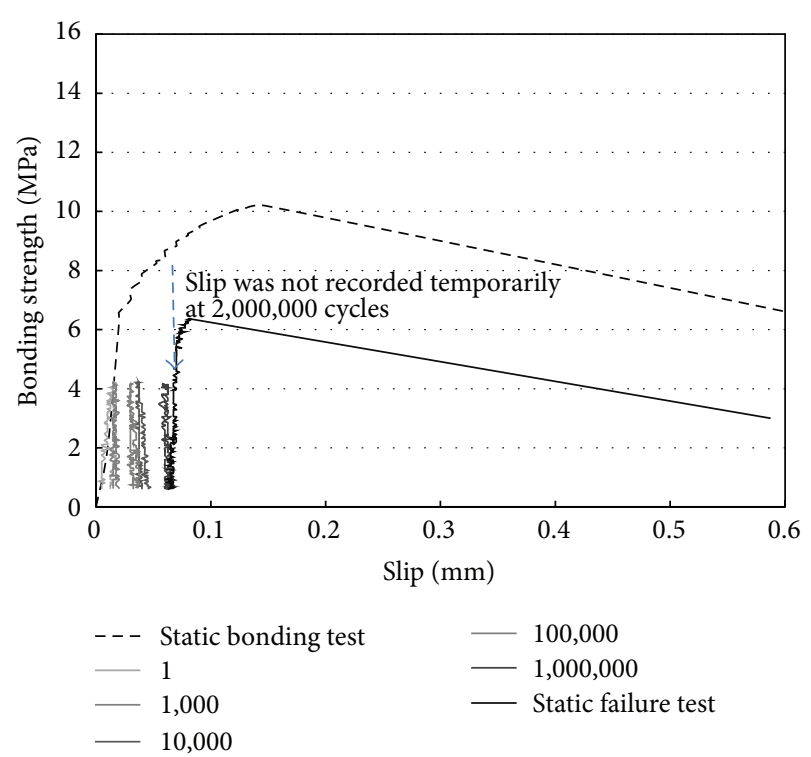

FIGURE 10: Bond stress-slip relationship of the $10 d_{b}$ specimen under $70 \%$ stress level of the ultimate strength.

reinforcing bar was better than that of the GFRP reinforcing bar, considering bars of the same diameter, due to enhanced shear action of the GFRP rib. For the fatigue test, as the number of repeated cycles increased, the residual slip amount also increased, although its scale was very small. The $10 d_{b}$ specimen showed less than $50 \%$ slip versus the $5 d_{b}$ specimen at the ultimate bond strength. As the bond length increased, the bond strength decreased $[13,14]$. The bond strength can be defined as a mechanical performance of the rib. As the bond length is shorter, the bond strength at the rib is increased. If the bond length is longer, however, the bond strength at the rib is decreased due to the stress distribution. Consequently, the ribs with longer bond lengths can stably contribute stress transference to the concrete with much higher tensile stress of the reinforcing bar than with a short bond length.

4.3. Fatigue Limit of GFRP Reinforcing Bar Bonding. Comparing the $10 d_{b}$ specimen with the $5 d_{b}$ specimen at 2,000,000 cycles in Figures 8 and 9, the maximum slip of the $10 d_{b}$ specimen was found to be less than that of the $5 d_{b}$ specimen. This indicated that as the bond length was longer, the maximum bond strength resulted in the shorter slip. This was confirmed with experimental results of maximum slips of $0.175 \mathrm{~mm}$ for $5 d_{b}$ and $0.083 \mathrm{~mm}$ for $10 d_{b}$. The slip limit for longer bond length specimen of the GFRP reinforcing bar at 2,000,000 cycles can be estimated; it will diminish with a decreasing rate close to that for the $5 d_{b}$ and $10 d_{b}$ specimens.

For the fatigue test, the fatigue limit state can be estimated from the S-N curve based on Miner's theory, which is based mostly on linear cumulative damage concepts, as proposed by Palmgren and Miner [15]. Figure 11 shows the log-scaled S-N curve and regression analysis from the results of the fatigue tests for the $5 d_{b}$ and $10 d_{b}$ specimens. For S-N curve analysis, the fatigue limit of the bonding of the GFRP reinforcing bar can be investigated for pullout failure. The fatigue limit 
TABLE 3: Estimation of fatigue limit stress based on a regression analysis.

\begin{tabular}{lcc}
\hline Specimens & Regression formula & $\begin{array}{c}\text { Fatigue limit stress } \\
\text { at 10,000,000 cycles }\end{array}$ \\
\hline $5 d_{b}$ & $-2.65 \ln (x)+110.07$ & $68.0 \%$ \\
$10 d_{b}$ & $-3.119 \ln (x)+115.26$ & $65.0 \%$ \\
\hline
\end{tabular}

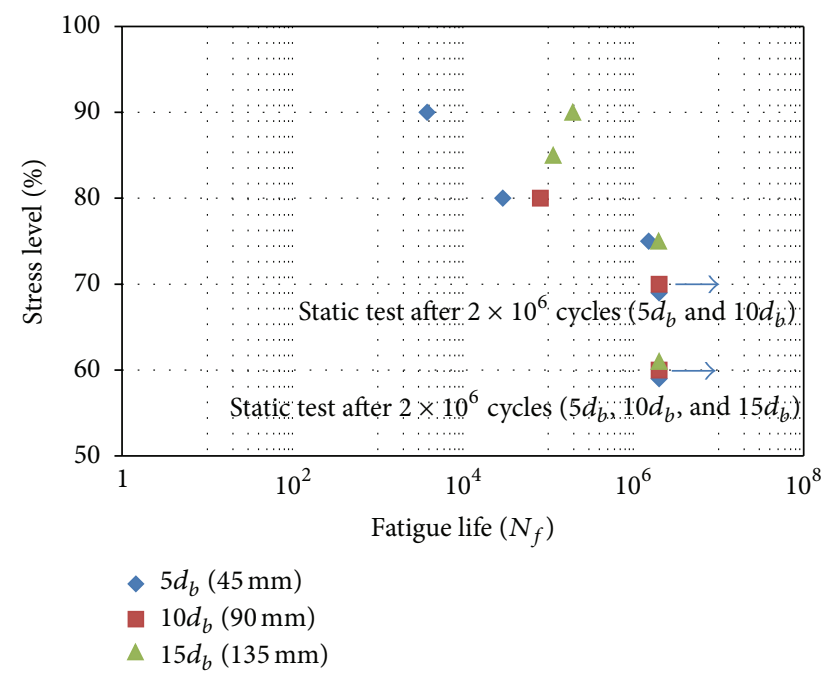

FIGURE 11: S-N relationship of the flexural bond test specimens.

state of bonding is useful in designing and analyzing flexural reinforced concrete members, especially those reinforced with GFRP reinforcing bars. Table 3 shows the estimated fatigue limit stress by regression analysis.

\section{Test Results of the Variable-Amplitude Loading Test}

Due to the uncertain characteristic of the bond strength of the FRP reinforcing bar, investigating only monotonic loaded fatigue test is not sufficient. Authors conducted the flexural fatigue bond test under variable-amplitude loading condition to evaluate the real bond fatigue performance. One can simulate the accelerated effect of accumulated damage on bond strength of the GFRP reinforcing bar by subjecting it to variable-fatigue loading conditions. Table 4 shows the applied load levels and cases for the variable-amplitude loading test. Each specimen was tested for the designated variable loading case, and in total six specimens were tested for $5 d_{b}$ and $15 d_{b}$. Loading was applied based on the designated proportion of the maximum bond strength, as in the monotonic loading test. The loading sequence, however, was set as shown in Table 4 . The minimum load level was considered to be $15 \%$ of the failure number of cycles $\left(N_{f}\right)$ and the variable-amplitude load was initiated at this level. Variable load cases 1 and 2 are the upward (low 75\% to high 80\%) and downward (high $80 \%$ to low $75 \%$ ) load cases, respectively. These loading cases were performed to investigate the accumulated damage effect according to the loading sequence magnitude. Variable load case 3 is an upward case including two steps of the minimum load level of $0.15 N_{f}$. The experimental results from these load cases were analyzed using the linear damage theory of fatigue.

Figure 11 shows the relationship of applied bond stress and unbounded end slip for test specimens with bond lengths of $45 \mathrm{~mm}$ and $135 \mathrm{~mm}$. The two specimens have different performance limits, such as pullout and concrete splitting failure. For this reason, the unloaded end slips before the concrete splitting failure of the $15 d_{b}$ specimen were compared with those of the $5 d_{b}$ specimen. The $5 d_{b}$ specimen showed a sudden increase in slip in the downward load case (80 to 75) as it approached failure. The $15 d_{b}$ specimen, however, showed no such sudden increase and the slip at failure was stable at $0.2 \mathrm{~mm}$. As the applied load level was increased, the $5 d_{b}$ specimen with the shorter bond length was more sensitive to causing a larger slip. Figure 12 shows the relationship between cumulative end slip and normalized relative fatigue life $\left(n_{f} / N_{f}\right)$.

Figure 13 illustrates the cumulative end-slip increase according to the relative fatigue life for the monotonic and the variable-amplitude loading test. The cumulative end slip under variable-amplitude loading condition, compared with that of monotonic loading condition, exhibited a sudden increase of slip at the moment of the specific fatigue life. In the case of the FRP reinforcing bar, verifying the bond characteristics based on bond length is more important than the conventional steel reinforcing bar subjected to the variable-amplitude load regarding the real loading frequency of the traffic volume. Table 5 summarizes the result of estimation of fatigue life by the Palmgren-Miner rule, which is commonly used to calculate the cumulative fatigue damage on the following equation:

$$
D=\sum_{i=1}^{k} \frac{n_{i}}{N_{i}}
$$

where $n_{i}=$ number of loading cycles at a given stress level sigma $i, N_{i}=$ number of cycles to failure at sigma $i$, and $D=$ total damage on fatigue (usually considered to be 1 at fatigue failure).

\section{Results and Discussions}

The bond length of the GFRP reinforcing bar in this study is "safer" than that mandated by ACI 440 1R-03, and the outer ribs can sufficiently resist the shear friction against the tensile stress of the GFRP reinforcing bar. For purposes of structural designs, the bond characteristics should also be confirmed when subjected to repeated loading conditions.

The work energy of the pullout action of FRP reinforcing bar indicates the capacity for energy dissipation at the interface between concrete and the surface of reinforcing bar. While the bond strength decreases, according to the increase in bond length, total work energy, defined by the area of loads and slip curves of the specimen, increases (Figure 5). This means that each bond stress on the rib is released and bonding force is enhanced as the bond length is increased. Appropriate level of bond length may be recommended with this energybased analysis. 

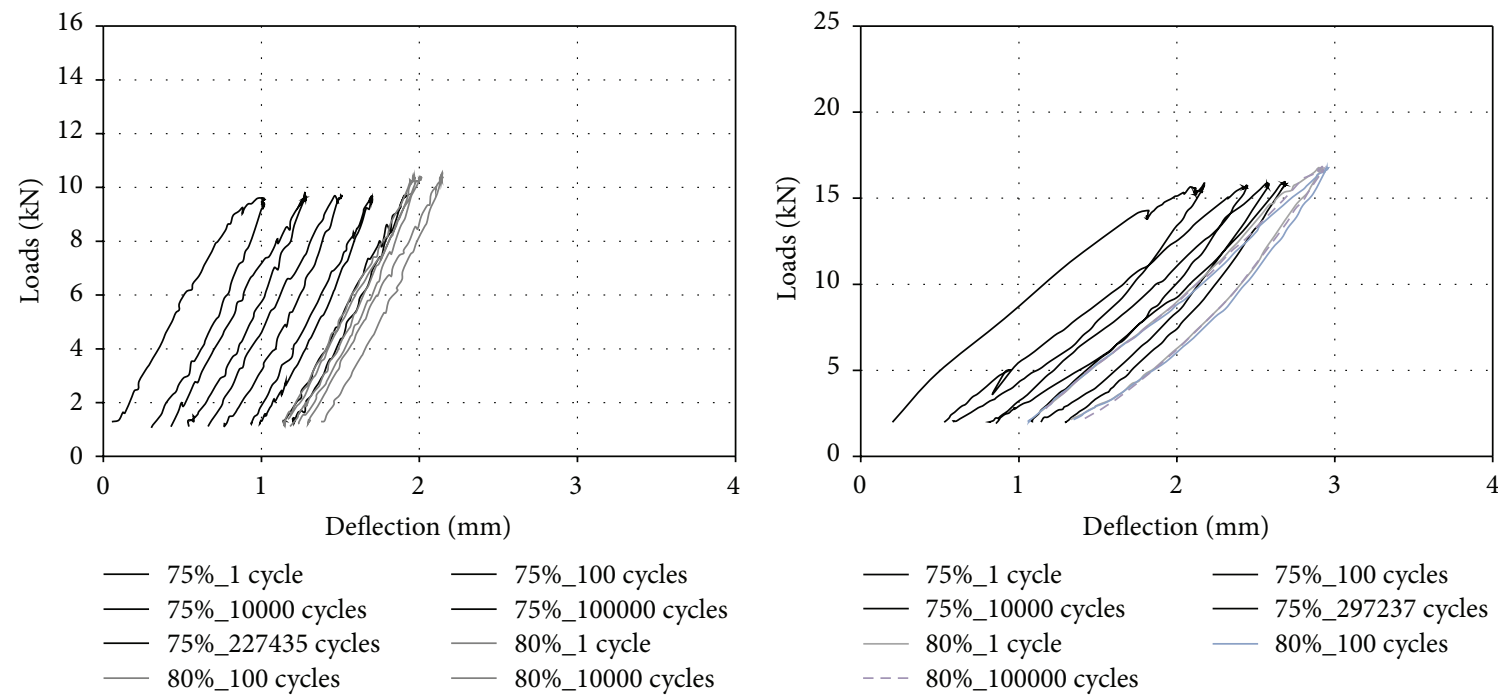

(a) $0.75 \tau_{\max } \rightarrow 0.80 \tau_{\max }\left(5 d_{b}\right)$
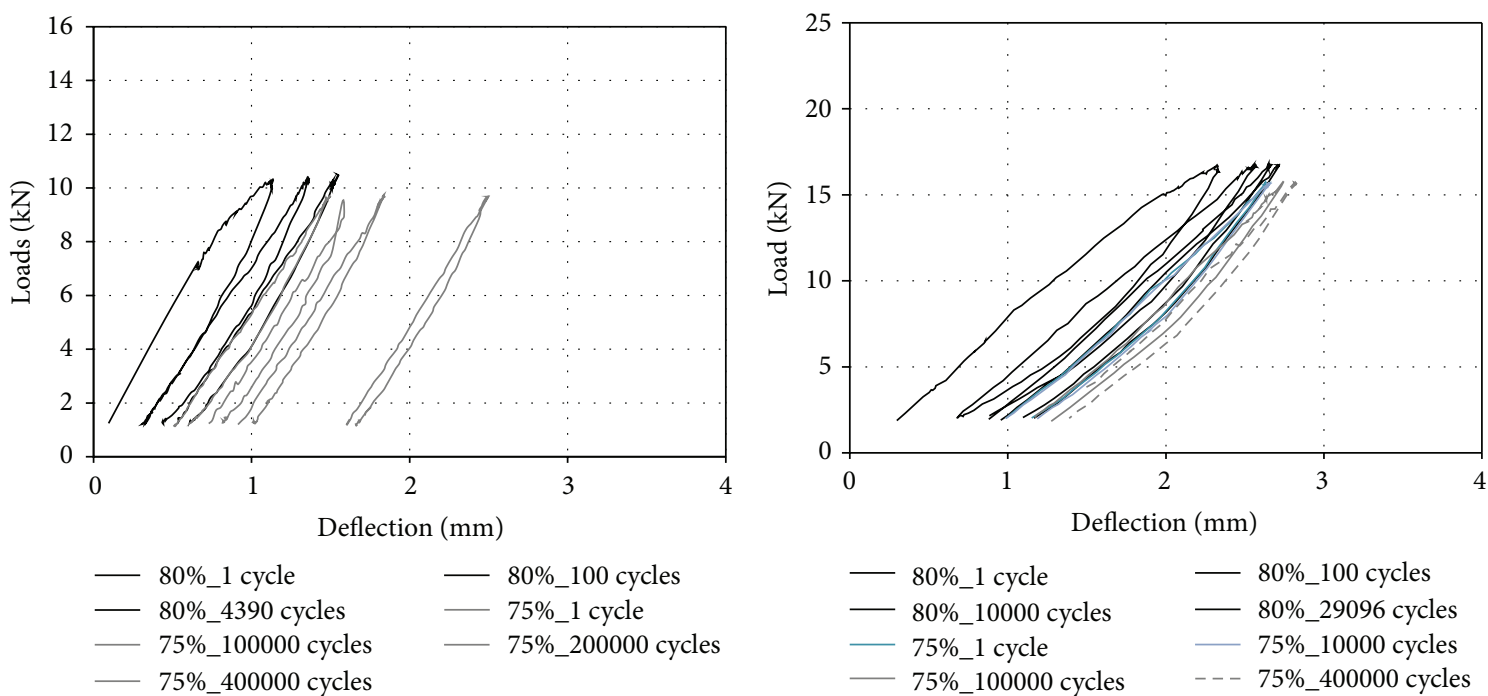

(c) $0.80 \tau_{\max } \rightarrow 0.75 \tau_{\max }\left(5 d_{b}\right)$

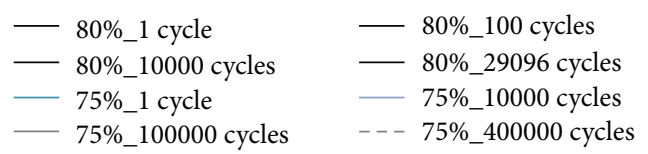

(d) $0.80 \tau_{\max } \rightarrow 0.75 \tau_{\max }\left(15 d_{b}\right)$
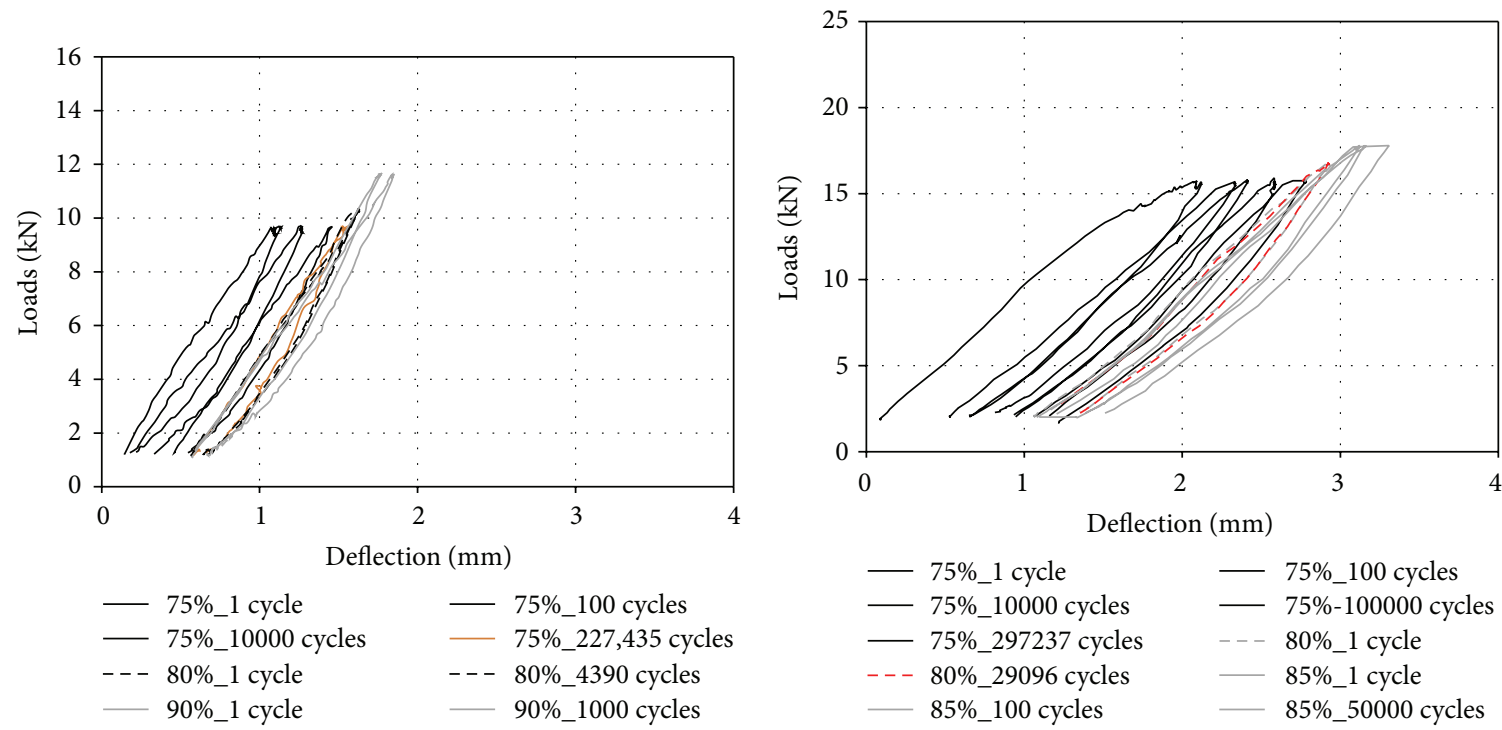

(e) $0.75 \tau_{\max } \rightarrow 0.80 \tau_{\max } \rightarrow 0.90 \tau_{\max }\left(5 d_{b}\right)$

(f) $0.75 \tau_{\max } \rightarrow 0.80 \tau_{\max } \rightarrow 0.85 \tau_{\max }\left(15 d_{b}\right)$

FIGURE 12: Relationship between applied loads and cumulative mid-deflection under various loading steps. 
TABLE 4: Stress level of the fatigue bond test.

\begin{tabular}{lcc}
\hline Load levels and cases & Applied load history & Loading sequences \\
\hline Variable load case 1 & $0.75 \tau_{\max }\left(0.15 N_{f}\right) \rightarrow 0.8 \tau_{\max }$ (until failure) & Low $\rightarrow$ high \\
Variable load case 2 & $0.8 \tau_{\max }\left(0.15 N_{f}\right) \rightarrow 0.75 \tau_{\max }$ (until failure) & High $\rightarrow$ low \\
Variable load case 3 & $0.75 \tau_{\max }\left(0.15 N_{f}\right) \rightarrow 0.8 \tau_{\max }\left(0.15 N_{f}\right) \rightarrow 0.85 \tau_{\max }$ or 0.85 $\tau_{\max }$ (until failure) & Low $\rightarrow$ high 1 $\rightarrow$ high 2 \\
\hline
\end{tabular}

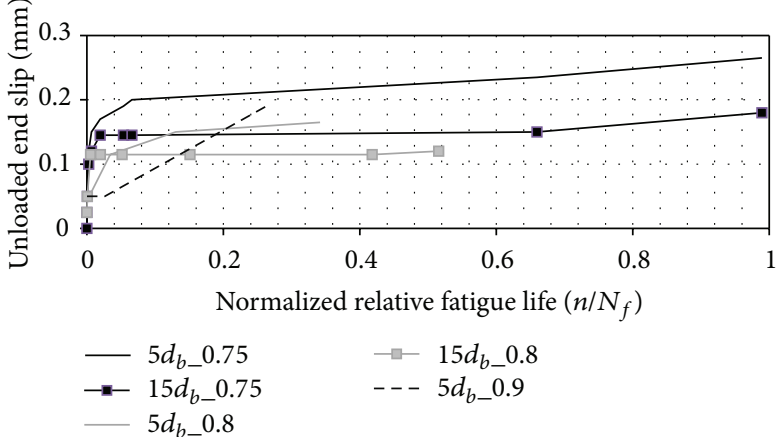

(a)

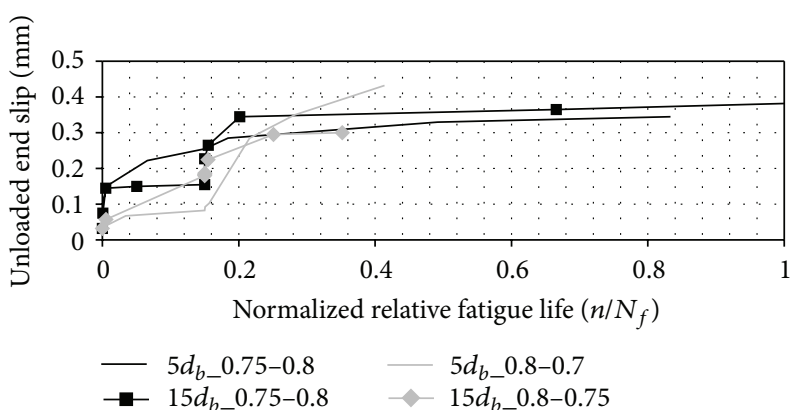

(b)

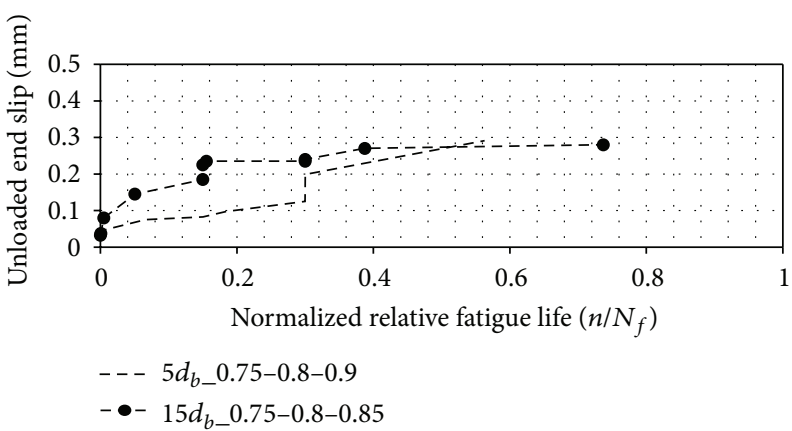

(c)

FIGURE 13: Cumulative end-slip increase according to the relative fatigue life.

TABLE 5: Linear cumulative damage of the specimens under an amplitude loading condition.

\begin{tabular}{cccccc}
\hline & Load case & $D_{1}$ & $D_{2}$ & $D_{3}$ & $\sum D_{i}$ \\
\hline \multirow{4}{*}{$5 d_{b}$} & Case 1 & 0.15 & 0.89 & - & 1.04 \\
& Case 2 & 0.15 & 0.27 & - & 0.42 \\
& Case 3 & 0.15 & 0.15 & 0.96 & 1.26 \\
\hline \multirow{3}{*}{$15 d_{b}$} & Case 1 & 0.15 & 1.16 & - & 1.31 \\
& Case 2 & 0.15 & 0.21 & & 0.36 \\
& Case 3 & 0.15 & 0.15 & 0.71 & 1.01 \\
\hline
\end{tabular}

Compared with the static loading test, the bond strength decreased markedly for the $5 d_{b}$ and $10 d_{b}$ specimens, up to a maximum $63-70 \%$, as noted above. This degraded bond strength was caused by the residual slip resulting from the repeated loading. Repeated loading of a flexural member reinforced with GFRP reinforcing bar was concluded to affect the loss of bond strength, which is a factor usually considered in the design of the bond.

At the assumed fatigue cycles of 10,000,000, the fatigue limit stresses for $5 d_{b}$ and $10 d_{b}$ specimens were $68.0 \%$ and
$65.0 \%$, respectively. These results showed that the GFRP reinforcing bar had sufficient bond performance in a repeated loading state, such as vehicular traffic, to be used in the design of concrete flexural members.

Initial damage was calculated by considering the applied load level of $0.15 N_{f}$. For the total damage on fatigue, two apparent differences were detected. The low-high cases (cases 1 and 3) showed total damage over 1.0 according to test results of the fatigue failure. The high-low case (case 2), however, showed total damage still under 1.0 even though the specimen had already failed. This result indicates that the fatigue performance was more vulnerable when a high load is applied prior to a low load on the structure. The linear cumulative damage theory based on the Palmgren-Miner rule may not be appropriate for estimating the fatigue limit when subjected to variable-amplitude loading.

6.1. Reduction Factor of the Fatigue Bond Strength. From the fatigue bond test, the relationship between the reduction in bond strength and the residual slip at maximum bond strength in fatigue at 2,000,000 cycles was investigated. As the slip increased, the bond strength was found to decrease. 


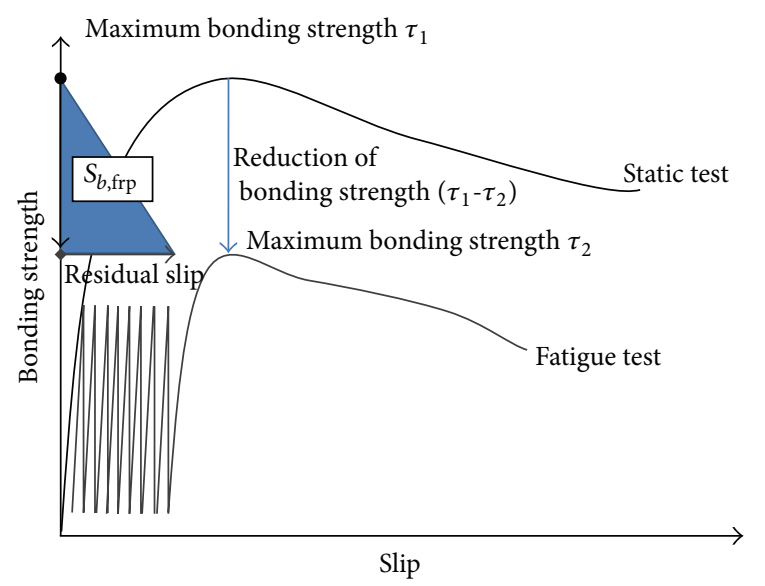

Figure 14: Diagram of the reduction factor of bond stiffness for an FRP reinforcing bar.

Thus, the reduction in bond strength was proportional to the amount of residual slip, which means that bond stiffness, according to repeated loading, decreases. This relationship can be redefined using an energy concept to calculate half the area of the $x-y$ graph.

In this study, a reduction factor for bond stiffness of the FRP reinforcing bar, $S_{b \text { frp }}$, can be defined by an energy concept using the area of the shaded section in Figure 14. The conceptual formula is as follows:

$$
\begin{aligned}
& S_{b_{\text {ffrp }}} \\
& \quad=\frac{1}{2}\left[\text { a reduction in bond strength }\left(\tau_{1}-\tau_{2}\right)(\mathrm{MPa})\right. \\
& \quad \times \text { the residual slip }(\mathrm{mm})]
\end{aligned}
$$

$S_{b_{\text {frp }}}$ is suggested for evaluating the reduced capacity in bonding of an FRP reinforcing bar reinforced in a concrete flexural member when it is serviced under an ambient repeated loading state such as vehicle load. The performance standard for fatigue bonding of the FRP reinforcing bar should be used in designing the member. The reduced capacity under fatigue loading must be evaluated quantitatively because of the various types of rib shapes for the FRP reinforcing bar so that the rib shapes directly affect determining the bond capacity, especially in fatigue loading. By applying (3) to the results of the $5 d_{b}$ and $10 d_{b}$ specimens, $S_{b \text { frp }}$ for the $5 d_{b}$ and $10 d_{b}$ specimens was found to be 0.41 and 0.16 , respectively, which means that as the bond length is longer, the reduction in bond stiffness decreases. Thus, a quantitative evaluation indicated that the bond stress can be transferred to the concrete well under fatigue loading.

Using this factor for the reduced capacity of bonding of FRP reinforcing bars, one can check the reduction rate of bonding of FRP reinforcing bars under fatigue loading. For a more reliable evaluation, $S_{b \text { frp }}$ should be formulated as a function of various experimental data so that the nonlinearity of the relationship between the reduced bond strength and the residual slip can be confirmed.

\section{Conclusions}

In this study, we investigated the bond performance of GFRP reinforcing bars under fatigue loading. The fatigue test was conducted until 2,000,000 cycles, and the bond strength and slip relationship were examined. The conclusions are as follows.

(1) For the static loading test, the bond length was evaluated as $225 \mathrm{~mm}$, whereas it was $317 \mathrm{~mm}$ according to ACI 440 1R-03. The bond length of the GFRP reinforcing bar in this study well satisfied the ACI 440 1R-03 limit, and the outer ribs sufficiently resisted the shear friction against the tensile stress of the GFRP reinforcing bar. Each bond stress on the rib is released and bonding force is enhanced as the bond length is increased. Appropriate level of bond length may be recommended with this energy-based test result. For the purposes of structural design, these bond characteristics should be further confirmed when subjected to repeated loading conditions.

(2) For the pullout failure specimens, the bond strengths at failure testing after 2,000,000 cycles were $10.4 \mathrm{MPa}$ and $6.5 \mathrm{MPa}$, respectively, which is $63-70 \%$ when compared with those from the static bond test. This was caused by repeated stress on the bond surface so that fatigue stress weakened the adhesive capacity between the concrete and the surface of the GFRP reinforcing bar. Thus, FRP bonding in designs should be checked with respect to the fatigue behavior of the flexural member.

(3) In this study, a reduction factor for bond stiffness for the FRP reinforcing bar, $S_{b \text { frp }}$, was suggested experimentally. Using this factor for the reduced capacity of bonding of FRP reinforcing bars, one can quantitatively check the expected reduced bonding of the FRP reinforcing bar under fatigue. For a more reliable evaluation, $S_{b-\text { frp }}$ should be formulated as a function of various experimental data so that the nonlinearity of the relationship between the reduced bond strength and residual slip can be confirmed.

(4) For the variable loading test, the linear cumulative damage theory on GFRP bonding was found to perhaps not be appropriate to estimate the fatigue limit when subjected to variable-amplitude loading. The GFRP reinforcing bar was concluded to have sufficient bond performance in a repeated loading state, such as vehicular traffic; that is, it can be used in designing concrete flexural members. In future studies, fatigue limit estimation should be researched for bonding of GFRP reinforcing bars under ambient loading conditions.

\section{Conflict of Interests}

The authors declare that there is no conflict of interests regarding the publication of this paper.

\section{Acknowledgments}

This work was supported by research grants of Korea Institute of Marine Science \& Technology Promotion (PJT200493) and Korea Institute of Energy Technology Evaluation and Planning (0000000015513). 


\section{References}

[1] E. Cosenza, G. Manfredi, and R. Realfonzo, "Behavior and modeling of bond of FRP rebars to concrete," Journal of Composites for Construction, vol. 1, no. 2, pp. 40-51, 1997.

[2] E. Cosenza, G. Manfredi, and R. Realfonzo, "Development length of FRP straight rebars," Composites, Part B: Engineering, vol. 33, no. 7, pp. 493-504, 2002.

[3] Z. Achillides and K. Pilakoutas, "Bond behavior of fiber reinforced polymer bars under direct pullout conditions," Journal of Composites for Construction, vol. 8, no. 2, pp. 173-181, 2004.

[4] M. Baena, L. Torres, A. Turon, and C. Barris, "Experimental study of bond behaviour between concrete and FRP bars using a pull-out test," Composites Part B: Engineering, vol. 40, no. 8, pp. 784-797, 2009.

[5] Z. He and G.-W. Tian, "Probabilistic evaluation of the design development length of a GFRP rod pull-out from concrete," Journal of Engineering Structures, vol. 33, no. 10, pp. 2943-2952, 2011.

[6] C. G. Papakonstantinou, P. N. Balaguru, and Y. Auyeung, "Influence of FRP confinement on bond behavior of corroded steel reinforcement," Cement and Concrete Composites, vol. 33, no. 5, pp. 611-621, 2011.

[7] Y. Ding, X. Ning, Y. Zhang, F. Pacheco-Torgal, and J. B. Aguiar, "Fibres for enhancing of the bond capacity between GFRP rebar and concrete," Construction and Building Materials, vol. 51, pp. 303-312, 2014.

[8] British Standard, "Determination of the bond behavior between reinforcing steel and autoclaved aerated concrete by the beam test," BS EN EN 12269-1, 2000.

[9] J. Sim, H. Oh, D. Moon, and M. Ju, "A hybrid fiber reinforced plastic rebar having a optic sensor for concrete," Patent No. 100709292, 2006 (Korean).

[10] D. Moon, Bond behavior of newly developed deformed GFRP bars [Ph.D. thesis], Hanyang University, Seoul, Republic of Korea, 2004.

[11] H. Oh, J. Sim, T. Kang, and H. Kwon, "An experimental study on the flexural bonding characteristic of a concrete beam reinforced with a GFRP rebar," KSCE Journal of Civil Engineering, vol. 15, no. 7, pp. 1245-1251, 2011.

[12] B. Tighiouart, B. Benmokrane, and D. Gao, "Investigation of bond in concrete member with fibre reinforced polymer (FRP) bars," Construction and Building Materials, vol. 12, no. 8, pp. 453-462, 1998.

[13] E. Makitani, I. Irisawa, and N. Nishiura, "Investigation of bond inconcrete member with fibre reinforced polymer bars," in Proceedings of the International Symposium Fibre-ReinforcedPlastic Reinforcement for Concrete Structures, ACI SP-138, pp. 315-331, 1993.

[14] A. Nanni, M. M. Al-Zahrani, S. U. Al-Dulaijan, C. E. Bakis, and T. E. Boothby, "Bond of FRP reinforcement to concrete," in Proceedings of the 2nd International RILEM Symposium (FRPRCS-2 '95), pp. 135-145, London, UK, 1995.

[15] J. Schijve, Fatigue of Structures and Materials, Kluwer Academic Publishers, Dordrecht, The Netherlands, 2001. 

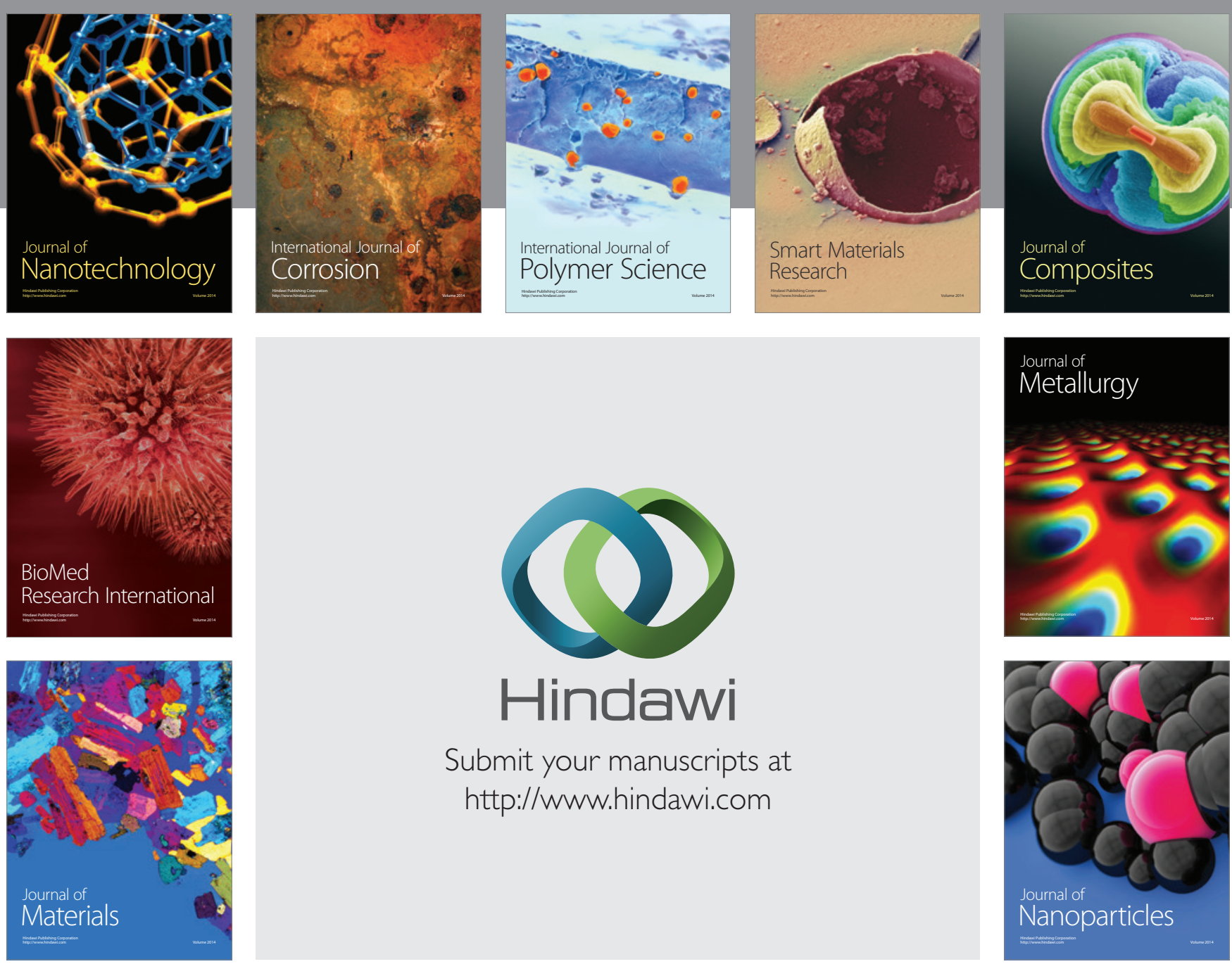

Submit your manuscripts at http://www.hindawi.com
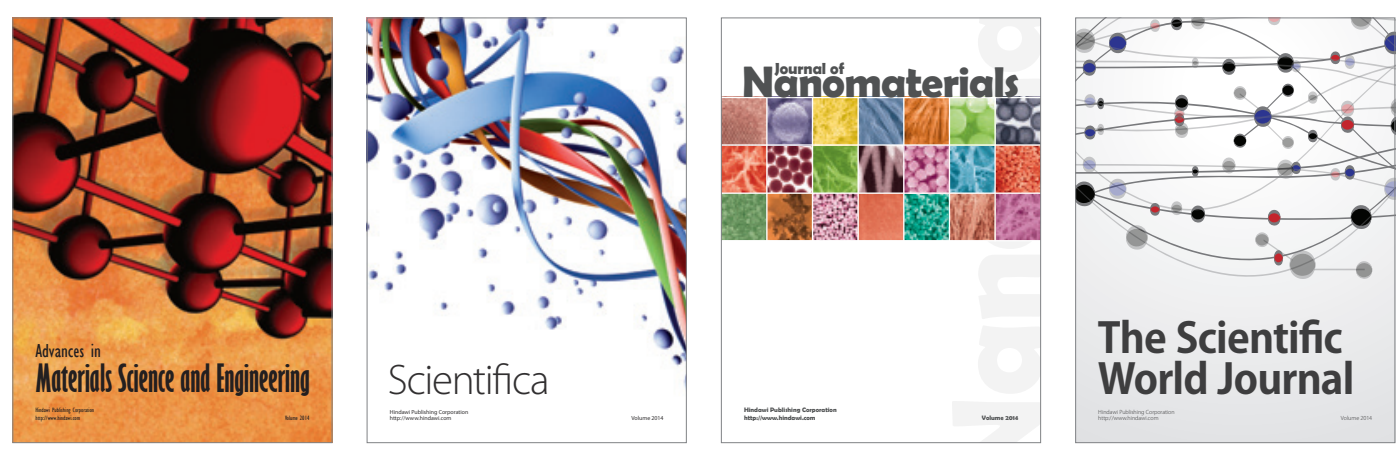

\section{The Scientific World Journal}
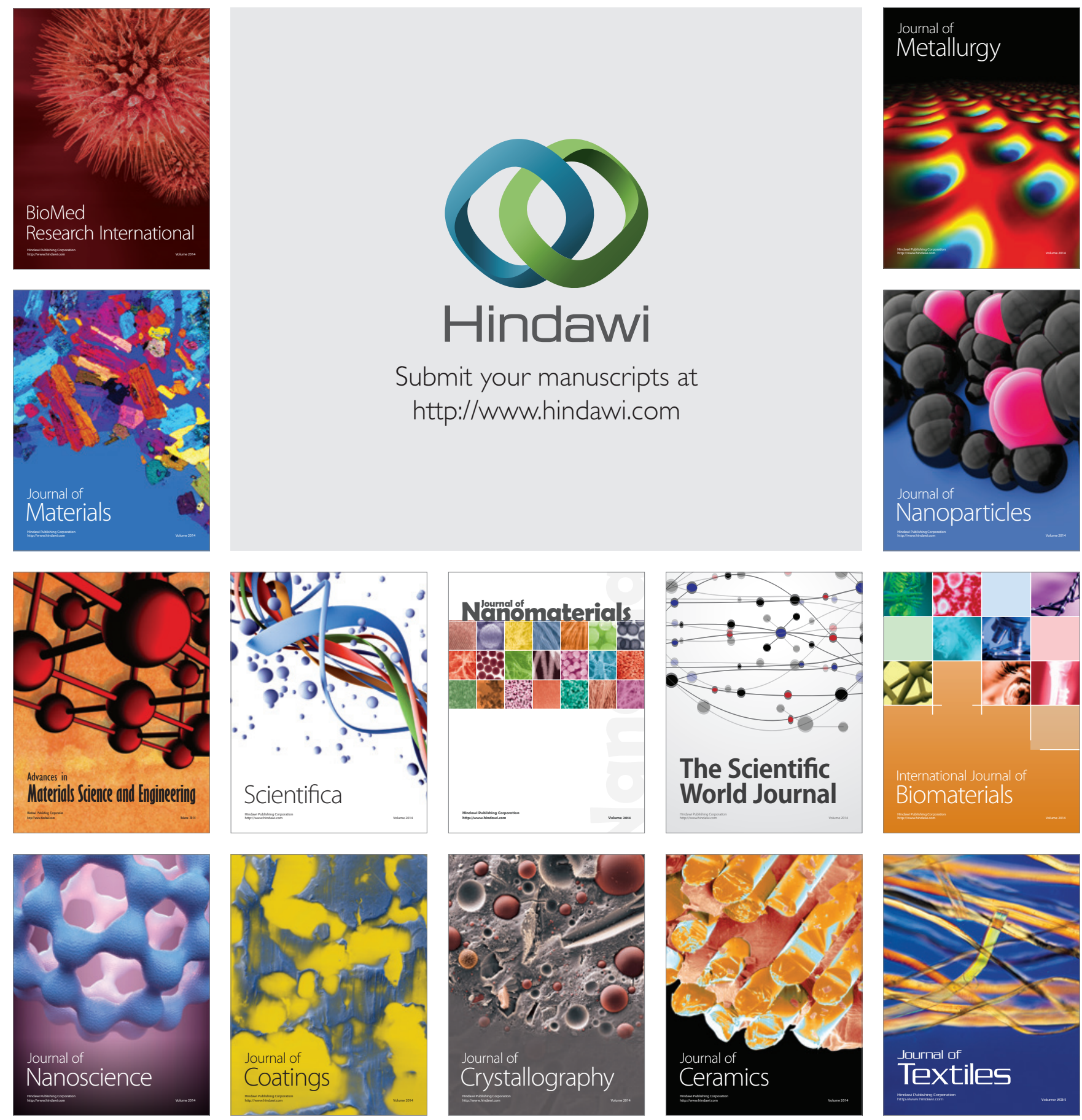